Louisiana State University

LSU Digital Commons

$9-1-2004$

\title{
The Chlamydomonas reinhardtii proteins Ccp1 and Ccp2 are required for long-term growth, but are not necessary for efficient photosynthesis, in a low- $\mathrm{CO}_{2}$ environment
}

\author{
Steve V. Pollock \\ Louisiana State University \\ Davey L. Prout \\ Louisiana State University \\ Ashley C. Godfrey \\ Louisiana State University \\ Stephane D. Lemaire \\ Institut des Sciences des Plantes de Paris-Saclay \\ James V. Moroney \\ Louisiana State University
}

Follow this and additional works at: https://digitalcommons.Isu.edu/biosci_pubs

\section{Recommended Citation}

Pollock, S., Prout, D., Godfrey, A., Lemaire, S., \& Moroney, J. (2004). The Chlamydomonas reinhardtii proteins $\mathrm{Ccp} 1$ and $\mathrm{Ccp} 2$ are required for long-term growth, but are not necessary for efficient photosynthesis, in a low- $\mathrm{CO}_{2}$ environment. Plant Molecular Biology, 56 (1), 125-132. https://doi.org/ $10.1007 / \mathrm{s} 11103-004-2650-4$

This Article is brought to you for free and open access by the Department of Biological Sciences at LSU Digital Commons. It has been accepted for inclusion in Faculty Publications by an authorized administrator of LSU Digital Commons. For more information, please contact ir@lsu.edu. 


\title{
The Chlamydomonas reinhardtii proteins Cep1 and Ccp2 are required for long-term growth, but are not necessary for efficient photosynthesis, in a low- $\mathrm{CO}_{2}$ environment
}

\author{
Steve V. Pollock ${ }^{1,2, *}$, Davey L. Prout $\mathrm{Jr}^{1}$, Ashley C. Godfrey ${ }^{1}$, Stephane D. Lemaire ${ }^{3}$ \\ and James V. Moroney ${ }^{1}$ \\ ${ }^{1}$ Department of Biological Science, Louisiana State University, Baton Rouge, LA 70803, USA (*author for \\ correspondence; e-mail Pollock@lsu.edu); ${ }^{2}$ Present address: Department of Plant Biology, Carnegie Insti- \\ tution of Washington, 260 Panama street, Stanford, CA 94305, USA $;^{3}$ Institut de Biotechnologie des Plantes, \\ UMR 8618 CNRS, Université Paris-Sud, 91405 Orsay Cedex, France
}

Received 24 March 2004; accepted in revised form 30 August 2004

Key words: bicarbonate transport, carbon concentrating mechanism, Chlamydomonas reinhardtii, RNAi silencing

\begin{abstract}
The unicellular green alga Chlamydomonas reinhardtii acclimates to a low- $\mathrm{CO}_{2}$ environment by modifying the expression of a number of messages. Many of the genes that increase in abundance during acclimation to low- $\mathrm{CO}_{2}$ are under the control of the putative transcription factor Cia5. C. reinhardtii mutants null for cia5 do not express several of the known low- $\mathrm{CO}_{2}$ inducible genes and do not grow in a low- $\mathrm{CO}_{2}$ environment. Two of the genes under the control of Cia5, Ccp1 and Ccp2, encode polypeptides that are localized to the chloroplast envelope and have a high degree of similarity to members of the mitochondrial carrier family of proteins. Since their discovery, Ccp1/2 have been candidates for bicarbonate uptake proteins of the chloroplast envelope membrane. In this report, RNA interference was successful in dramatically decreasing the abundance of the mRNAs for $C c p 1$ and $C c p 2$. The abundance of the Ccp1 and Ccp2 proteins were also reduced in the RNAi strains. The RNAi strains grew slower than WT in a low-CO $\mathrm{CO}_{2}$ environment, but did not exhibit a mutant carbon concentrating phenotype as determined by the cells' apparent affinity for dissolved inorganic carbon. Possible explanations of this RNAi phenotype are discussed.
\end{abstract}

\section{Introduction}

When Chlamydomonas reinhardtii is grown in a low- $\mathrm{CO}_{2}$ environment, it induces a carbon dioxide concentrating mechanism (CCM) (Moroney and Somanchi, 1999). The CCM allows cells to perform photosynthesis at low levels of $\mathrm{CO}_{2}$ in the surrounding environment by increasing the concentration of $\mathrm{CO}_{2}$ around Rubisco. This increase in $\mathrm{CO}_{2}$ around Rubisco leads to an increased rate of photosynthesis and a decreased rate of photorespiration. When $C$. reinhardtii cells are shifted from a high- to low- $\mathrm{CO}_{2}$, the abundance of several mRNA transcripts change as the organism adjusts to its new surroundings (Burow et al., 1996; Somanchi et al., 1998; Im et al., 2003).

The gene products for several of these messages that increase in abundance have been identified. The proteins of known identity include carbonic anhydrases, photorespiratory pathway enzymes, and light-harvesting complex components which change in abundance during acclimation to a low$\mathrm{CO}_{2}$ environment. However, many other low $\mathrm{CO}_{2-}^{-}$ inducible genes are predicted to encode proteins of unknown function. Two separate laboratories have independently isolated mutants of Cia5 (Moroney et al., 1989; Fukuzawa et al., 1998). C. reinhardtii cells that are mutant for Cia5 do not acclimate to a 
low- $\mathrm{CO}_{2}$ environment (Moroney et al., 1989). The cia5 mutant lacks the induction of dissolved inorganic carbon (DIC) transport, induction of Cahl, $M c a l$ and $M c a 2, C c p 1$ and $C c p 2, L c i l$, or any of the low- $\mathrm{CO}_{2}$ induced polypeptides. In addition, the upregulation of phosphoglycolate phosphatase and glycolate dehydrogenase, and down-regulation of Rubisco biosynthesis does not occur in cia5 (Moroney et al., 1989; Marek and Spalding, 1991; Spalding et al., 1991; Burow et al., 1996). The cia5 gene was recently cloned. It is constitutively expressed and encodes a protein of $76 \mathrm{KDa}$ that contains a putative zinc-finger motif that is crucial to its regulatory function (Fukuzawa et al., 2001; Xiang et al., 2001).

Two low- $\mathrm{CO}_{2}$ inducible proteins with a molecular mass of $36 \mathrm{kD}$ were purified from membrane fractions of C. reinhardtii (Spalding and Jeffrey, 1989). These two peptides are immunologically distinct from the low- $\mathrm{CO}_{2}$ inducible Cah1 protein which has a similar molecular weight (37 KDa) (Geraghty et al., 1990). Using ${ }^{35} \mathrm{~S}$ labeling of C. reinhardtii proteins, LIP-36, for low$\mathrm{CO}_{2}$ induced peptide, was localized to intact chloroplasts (Moroney and Mason, 1991) and then more specifically localized to chloroplast envelopes by Ramazanov et al. (1993). The LIP-36 protein was purified from $8 \mathrm{~L}$ of low- $\mathrm{CO}_{2}$ adapted cells of C. reinhardtii and sequenced. Using degenerate PCR primers, the cloning and over-expression of two genes encoding LIP-36 was achieved (Chen et al., 1997). The two genes were renamed to Ccp I and $C c p 2$, for chloroplast carrier proteins 1 and 2, and are predicted to encode proteins which are $95.7 \%$ identical, of 358 and 355 amino acids, respectively. Neither gene is expressed in the cia5 mutant background. The two proteins are predicted to have six transmembrane domains and are similar to proteins of the mitochondrial carrier protein super family. Proteins belonging to this family transport a wide variety of metabolites and ions (Walker and Runswick, 1993). Ccp1/2 are most similar to the Arabidopsis thaliana protein Bou (36\% identity). Bou is necessary for seedling development in the light and may be involved in a pathway that would be an alternative to the glyoxylate pathway (Lawand et al., 2002). Bou is most similar to the mitochondrial carnitine acyl carriers proteins. In animals and yeast, these transmembrane proteins are involved in the transport of lipid-derived molecules across mitochondrial membranes for energy and carbon supply.

The location of the Ccps in the chloroplast envelope, their induction in a low- $\mathrm{CO}_{2}$ environment, and their similarity to the mitochondrial carrier protein family has lead to the hypothesis that the Ccps may be involved in the active accumulation of DIC into the chloroplast. RNA interference (RNAi) has recently been utilized to silence the expression of several proteins in $C$. reinhardtii (for examples, see Sineshchekov et al., 2002; Koblenz et al., 2003). This paper describes the growth and photosynthetic characteristics of RNAi strains of $C$. reinhardtii that lack $C c p 1 / 2$ mRNA and protein in a low- $\mathrm{CO}_{2}$ environment to test the hypothesis that the Ccp proteins are required for optimal rates of photosynthesis in a low- $\mathrm{CO}_{2}$ environment.

\section{Materials and methods}

\section{Algal strains and transformation conditions}

Culture conditions were similar to those used previously (Rawat and Moroney, 1995). The strain D66 (nit $2^{-}, c w 15, m t^{+}$) was obtained from Rogene Schnell, University of Arkansas-Little Rock. rca-1 is a strain missing Rubisco activase that was generated by insertional mutagenesis as previously described (Pollock et al., 2003). For transformation, D66 cells were first grown in $100 \mathrm{ml}$ of TAP medium (Sueoka, 1960) for 2 days and then transferred to $500 \mathrm{ml}$ of TAP medium $24 \mathrm{~h}$ before the experiment. Cells were harvested and resuspended at a density of $2 \times 10^{8}$ cells ml ${ }^{-1}$ in TAP plus $60 \mathrm{mM}$ sucrose (Shimogawara et al., 1998). For electroporation, $1 \mu \mathrm{g}$ of pSL72-LIP36G1 DNA was linearized with $S t u \mathrm{I}$ and added to $250 \mu \mathrm{l}$ of the resuspended cells in an electroporation cuvette $(0.4 \mathrm{~cm}$ gap width BioRad). This mixture was held on ice for $15 \mathrm{~min}$. The electroporation setting conditions were a capacitance of $25 \mu \mathrm{F}$, the pulse control set to $\infty$, and no shunt resistor. The voltage was set to $2000 \mathrm{~V} \mathrm{~cm}^{-1}$ and the elapsed time was between 10 and $13 \mathrm{~ms}$. A BioRad electroporator Gene Pulser II was used. After electroporation, the cells were allowed to recover overnight in $10 \mathrm{ml}$ of TAP supplemented with $60 \mathrm{mM}$ sucrose in $30 \mu \mathrm{M}$ photons. Approximately 16-18 hours later, the cells were harvested and 
resuspended in $100 \mu \mathrm{l}$ of TAP. $6 \times 10^{7}$ cells were plated onto TAP + paromomycin $\left(5-15 \mu \mathrm{g} \mathrm{ml}^{-1}\right)$ plates. The cells were then allowed to grow in low-light conditions.

\section{Cloning of the RNAi construct}

Standard molecular biological techniques were utilized to clone the genomic DNA and the cDNA of Ccp1 into the pSL72 plasmid (Figure 1). pSL72 is a pBS vector where the $\mathrm{psa} D$ promoter is cloned between $K p n \mathrm{I}$ and $X h o \mathrm{I}$, and the psa $D$ terminator between $X b a \mathrm{I}$ and NotI. This promoter drives the expression of the AphVIII coding sequence cloned between $N d e \mathrm{I}$ and $E c o \mathrm{RV}$. The genomic DNA fragment was ligated to the inverted cDNA fragment at a $S c a$ I site common to both fragments. This fragment was cloned into the $E c o \mathrm{RV}$, alkaline phosphotase treated pSL72. The genomic DNA fragment contains exons and introns from exons 2 to exon 6. The cDNA fragment contains cDNA equivalent to the exons 2-6 in the genomic DNA fragment above.

\section{Photosynthesis assays}

Cultures were grown mixotrophically in $100 \mathrm{ml}$ of TAP media on a shaker set at $180 \mathrm{rpm}$ in moderate light. After $48 \mathrm{~h}$, the cultures were transferred to minimal medium without a carbon source and bubbled with $5 \% \mathrm{CO}_{2}$ in air for $24 \mathrm{~h}$. The cultures were then acclimated to low- $\mathrm{CO}_{2}$ by bubbling with air for 16-20 hours. All conditions were carried out under continuous light $\left(80 \mu \mathrm{E} \mathrm{m}^{2} \mathrm{~s}^{-1}\right)$.

The affinity of the wild-type and RNAi strains for external inorganic carbon was estimated as described by Pollock and Colman (2001). The

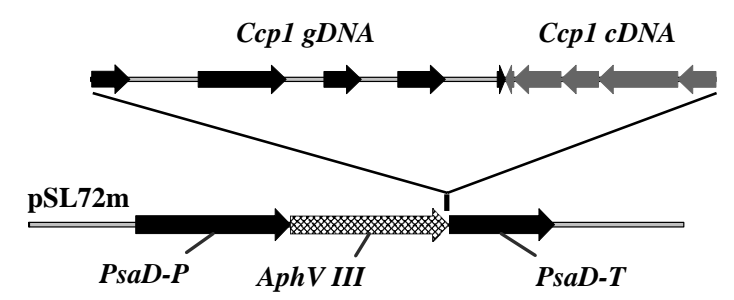

Figure 1. The $C c p 1$-RNAi construct. The inverted repeat was constructed by ligating a genomic DNA fragment (gDNA) to a complementary cDNA fragment in the opposite direction. The two fragments contain exons $2-5$ and the first 35 bps of exon 6 . The inverted repeat was cloned into the vector pSL72 between the AphVIII paromomycin resistance gene and the $P s a D$ terminator. photosynthetic rate of algal cells was measured with an oxygen electrode (Rank Brothers, Cambridge, UK). For the rcal related experiments, cells were transferred to the electrode chamber, where they were allowed to exhaust the medium $\left(50 \mathrm{mM} \mathrm{Na} / \mathrm{K}^{-}-\mathrm{PO}_{4}, \mathrm{pH} 7.8\right)$ of endogenous DIC until net $\mathrm{O}_{2}$ exchange was zero. For the $\mathrm{pH}$-related experiments, the biological buffers MES-KOH, MOPS-KOH, and HEPES-KOH were used for $\mathrm{pH}$ 6.3, 7.3, and 8.3, respectively, were used at a concentration of $25 \mathrm{mM}$.

\section{Results}

Ccpl and Ccp2 RNAi strains of C. reinhardtii require an environment that is enriched in $\mathrm{CO}_{2}$ to grow optimally

Figure 1 shows the RNAi construct for $C c p 1$. The pSL72 vector uses the PsaD promoter and terminator to express the AphVIII paromomycin resistance gene. An inverted repeat of the genomic region and cDNA of $C c p 1$ containing exons 2-6 was cloned into the vector pSL72 between the AphVIII gene and the PsaD terminator (Figure 1). The strain D66 was transformed with Stu1 linearized pSL72-RNAi construct and 500 transformants were selected in media containing the drug paromomycin. The 500 transformants were then replica plated onto minimal media in high- $\mathrm{CO}_{2}$ and low- $\mathrm{CO}_{2}$. Twenty-seven of the $500(5.4 \%)$ paromomycin transformants grew slower than the parent D66 in a low- $\mathrm{CO}_{2}$ environment, but grew normally in a high- $\mathrm{CO}_{2}$ environment (Figure 2). The high- $\mathrm{CO}_{2}$ requiring phenotypes were strongest within 2 months of generating the RNAi strains. The high- $\mathrm{CO}_{2}$ growth requirement became less severe over a period of months, but this did not correlate with an increase in abundance of the Ccp proteins (data not shown).

Ccpl and Ccp2 RNAi strains of C. reinhardtii have dramatically decreased levels of Ccp $m R N A$ and protein

From the pool of 27 transformants that grew slower in a low- $\mathrm{CO}_{2}$ environment, three transformants were selected for further analysis. Two additional paromomycin resistant transformants that were healthy in a low- $\mathrm{CO}_{2}$ environment were also 


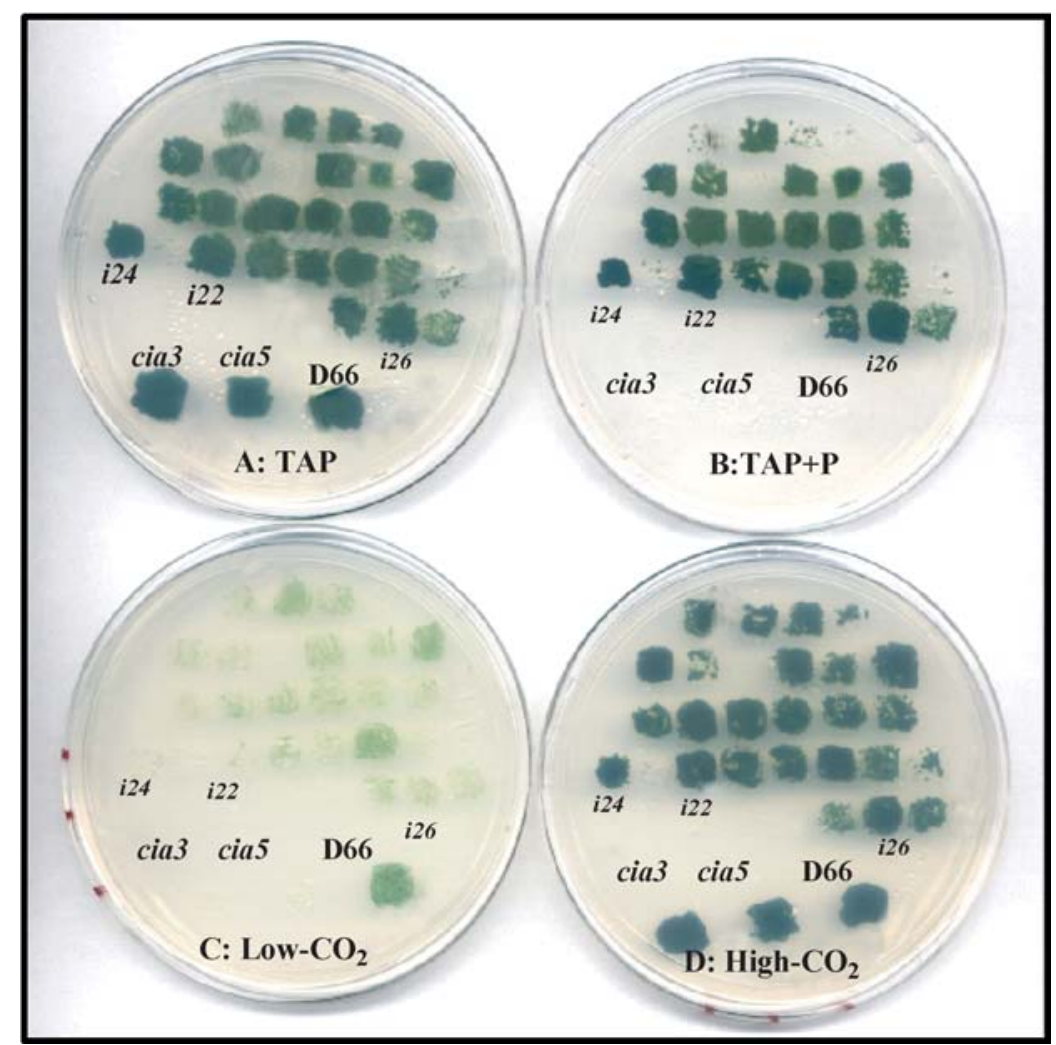

Figure 2. The secondary screening of the 27 paromomycin resistant transformants that grew slower than the parent D66 in a low-CO environment. The strains were grown in four environments. A: TAP, B: TAP plus paromomycin, C: minimal medium in $35 \mathrm{ppm} \mathrm{CO}_{2}$, and D: minimal medium in high- $\mathrm{CO}_{2}$. The two $\mathrm{CCM}$ mutants, cia3 and cia5, are shown as examples of high- $\mathrm{CO}_{2}$ requiring strains. The three RNAi strains, $i 22, i 24$, and $i 26$ were chosen for further analyses.

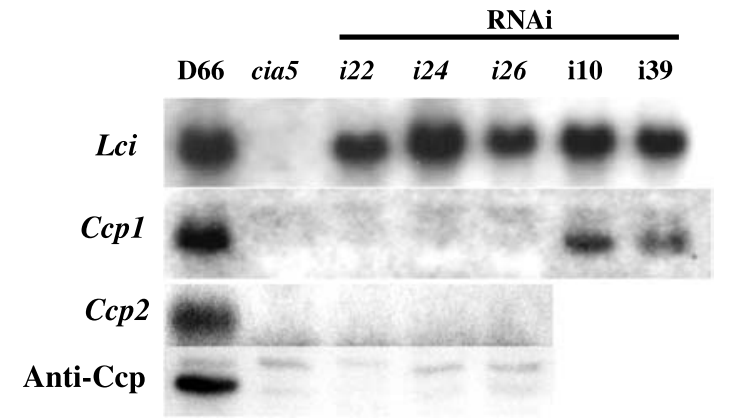

Figure 3. Northern blots measuring the abundance of the Lcil, Ccp1, and Ccp2 mRNA, and Western blot to measure the abundance of the Ccp protein for the parent (D66), the mutant $c i a 5$, the three high- $\mathrm{CO}_{2}$ requiring RNAi strains $(i 22, i 24$, and i26), and two of the healthy RNAi strains (i10 and i39). All strains were adapted to a liquid low- $\mathrm{CO}_{2}$ environment for $16-18 \mathrm{~h}$.

selected. Figure 3 shows the abundance of the Lcil, $C c p 1$, and $C c p 2$ mRNA and the Ccp protein for the parent (D66), the mutant cia5, the three sick RNAi strains (i22, i24, and i26), and two of the healthy RNAi strains (i10 and i39). Except for cia5, all of the analyzed strains expressed the low- $\mathrm{CO}_{2}$ inducible gene $L c i 1$. The $C c p 1$ and $C c p 2$ messages were absent in all three high- $\mathrm{CO}_{2}$ requiring RNAi transformants and cia5, whereas reduced levels were present in the i10 and i39 transformants. Western blot analysis using polyclonal antibodies raised against the Ccp protein from Chlamydomonas showed that the Ccp proteins were dramatically reduced in abundance in the high- $\mathrm{CO}_{2}$ requiring strains and cia5 as compared to the wildtype parent D66 (Figure 3). A higher molecular weight cross-reacting protein of unknown identity can also be seen on the Western blots.

\section{RNAi silenced strains exhibit wild-type photosynthetic kinetics}

Rates of photosynthesis as a function of the DIC concentration were measured for D66 and the 
RNAi strains acclimated to air levels of $\mathrm{CO}_{2}$ for $18 \mathrm{~h}$. When the RNAi strains were assayed at $\mathrm{pH}$ $6.3,7.3$, and 8.3, no difference in photosynthetic kinetics as compared to D66 WT were observed (Figure 4). In addition, the photosynthetic kinetics of the RNAi strains were compared to a WT-like paromomycin resistant strain and no differences were observed (data not shown).

The Ccpl RNAi construct was also transformed into the rcal strain. rcal contains a bleomycin resistance insert in the gene encoding Rubisco activase (Pollock et al., 2003). Since rcal already grows poorly on low- $\mathrm{CO}_{2}$, if the $\mathrm{Ccp} 1$ RNAi did result in a decrease in inorganic carbon uptake the decrease would be easier to measure. In fact $r c a l$ cells expressing the $C c p 1$ RNAi construct exhibited a sick on low- $\mathrm{CO}_{2}$ phenotype that was more severe than either the rcal mutant or the Ccp1 RNAi strains. The strains quickly became bleached and little growth was observable on agar media in low- $\mathrm{CO}_{2}$. However, these rcal cells expressing the $C c p 1$ RNAi construct exhibited no significant changes in the apparent affinities of the strains for DIC (Figure 5). Thus, the apparent affinity of the cells for DIC was not affected by the absence of the Ccp proteins.

\section{Discussion}

The Ccp proteins were initially recognized and named LIP36G1 and LIP36G2, as potential components of the $\mathrm{CCM}$ in $C$. reinhardtii 15 years ago (Spalding and Jeffrey, 1989). This
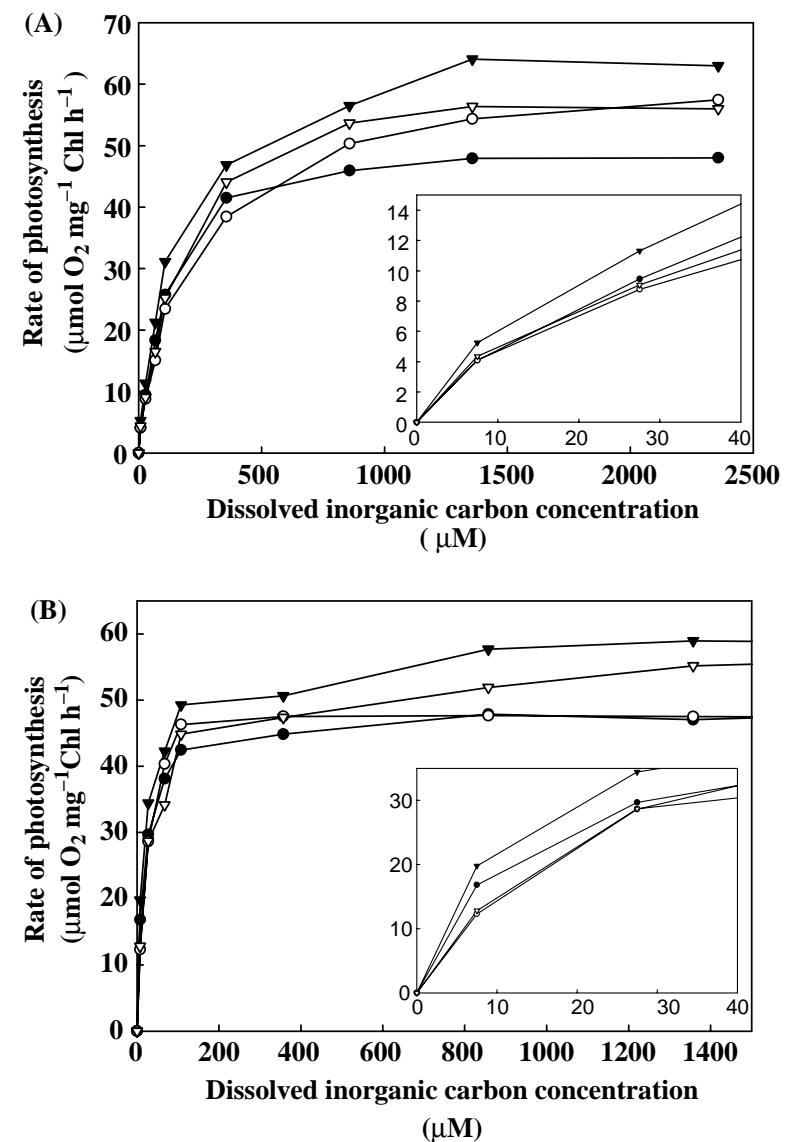

Figure 4. The effect of the dissolved inorganic carbon concentration on the rate of photosynthesis. A: air-grown D66 (๑), and the three RNAi strains $i 22(\bigcirc), i 24(\boldsymbol{\nabla})$, and $i 26(\nabla)$ tested at pH 8.3. B: air-grown D66 $(\bullet)$ and $i 22(\bigcirc)$ at pH 6.3, and D66 $(\boldsymbol{\nabla})$ and $i 22(\nabla)$ at $\mathrm{pH}$ 7.3. The inset graphs show the rates of oxygen evolution for the low concentrations of DIC. The chlorophyll concentrations ranged from 40 to $50 \mu \mathrm{g} \mathrm{ml}^{-1}$. The light intensity was approximately $800 \mu \mathrm{E} \mathrm{m}^{-2} \mathrm{~s}^{-1}$. 


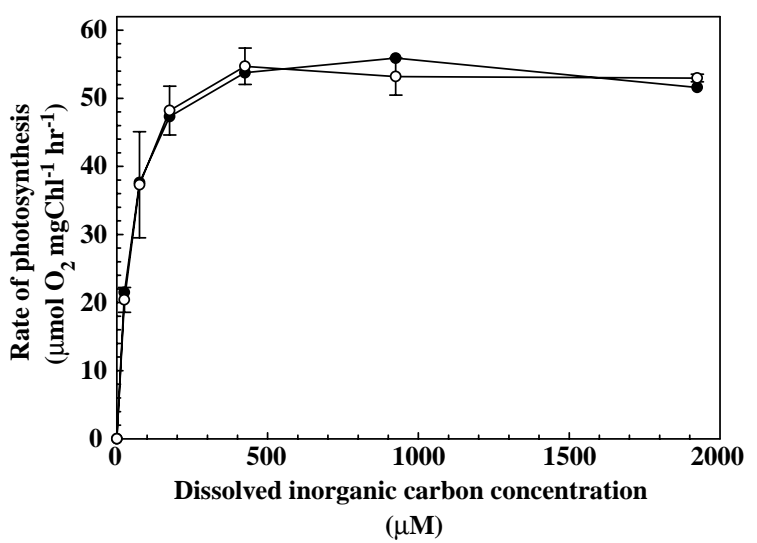

Figure 5. The effect of the dissolved inorganic carbon concentration on the rate of photosynthesis of air-grown $\operatorname{rcal}(\mathbf{)})$ and rcal that lacks the Ccp1 and Ccp2 proteins $(O)$. The error bars represent the standard deviation of the mean of three independent transformants.

report presents the first evidence that $\operatorname{Ccp} 1 / 2$ are not required for optimal rates of photosynthesis but are required for growth in a low- $\mathrm{CO}_{2}$ environment. The use of an RNAi construct (Figure 1) to target the degradation of $C$ cp $1 / 2$ mRNA was successful as measured by mRNA and protein abundance (Figure 3 ). Since there are two genes to target, $C c p 1$ and $C c p 2$, it is unlikely that a chemical or random-insertional mutagenesis strategy would lead to the silencing of both of the $C c p$ genes. On the other hand, RNAi can be utilized to target similar transcripts, as is the case in gene families, and is the case with the almost identical open reading frames of $C c p l$ and Ccp2.

In the three analyzed RNAi-strains that showed efficient silencing of $\mathrm{Ccpl} / 2$, the low- $\mathrm{CO}_{2}$ inducible transcript of Lcil was fully induced as compared to the wild-type parent D66, suggesting that the expression of other low- $\mathrm{CO}_{2}$ inducible genes is unaffected by the absence of $C c p$ mRNA. These results suggest that the RNAi silencing mechanism is specifically affecting the transcript abundance of $C c p 1$ and $C c p 2$. The absence of mRNA for $C c p 1$ and $C c p 2$ was mirrored by the reduction in the Ccp proteins detected using antibody raised against Ccp1, and the enhanced chemiluminescence detection method (Figure 3). Thus, the RNAi strategy was successful in targeting the $C c p 1 / 2$ mRNA to effectively reduce the abundance of $\mathrm{Ccp} 1 / 2$ protein to undetectable levels.
Surprisingly, RNAi silenced strains exhibited normal rates of photosynthesis at all tested concentrations of DIC, and over a range of $\mathrm{pHs}$ (Figures 4 and 5). This was not expected because the RNAi strains exhibited slower growth under low $\mathrm{CO}_{2}$ on solid media than wild-type cells (Figure 2). On the other hand, the RNAi strains grew at a rate similar to the wild-type parent in liquid cultures over a short time-course of $48 \mathrm{~h}$ in minimal media (data not shown). It is likely that the extremely low concentration of $\mathrm{CO}_{2}$ used during screening on solid media $\left(35 \mathrm{ppm} \mathrm{CO}_{2}\right.$ in air) was required to produce a long-term growth phenotype in the RNAi strains, whereas airadapted liquid cultures were only maintained for a maximum of $72 \mathrm{~h}$ since liquid cultures of C. reinhardtii reach stationary phase within a few days depleting the media of essential nutrients and limiting the effective light intensity.

In an attempt to magnify any potential CCM mutant phenotype of the RNAi strains, the RNAi vector was transformed into the $C$. reinhardtii Rubisco activase ( $r c a l$ ) mutant. In previous work (Pollock et al., 2003), the rcal mutant strain was shown to require a high- $\mathrm{CO}_{2}$ environment to photosynthesize optimally. Of particular utility to this report, in the rcal cia5 double mutant, where the CCM is not functional, cells were incapable of performing photosynthesis at low concentrations of DIC. Thus, by expressing the Ccpl RNAi construct in the rcal mutant background, any disruption in the active accumulation of DIC should be readily apparent. No significant changes in the apparent affinities of the strains for DIC were observed (Figure 5). Therefore, Ccpl and $\mathrm{Ccp} 2$ are required for growth in a low- $\mathrm{CO}_{2}$ environment, but not for the efficient operation of the CCM.

Are the Ccp proteins an integral component of DIC transport into the chloroplast of $\mathrm{C}$. reinhardtii?

By modifying the abundance of Ccp1 and Ccp2 several high- $\mathrm{CO}_{2}$ requiring strains of $C$. reinhardtii were generated (Figure 2). In cyanobacteria, four distinct uptake systems are required for efficient uptake of DIC (Omata et al., 2002; Shibata et al., 2002). When one of the cyanobacterial DIC uptake systems is mutated, the remaining three systems compensate for its loss and no mutant phenotype is observed. It is likely that $C$. rein- 
hardtii strains that lack the Ccp proteins adjust the global expression of several genes to compensate for the absence of the Ccp proteins. One possible explanation for these results is that the Ccps are involved in DIC uptake across the chloroplast envelope but additional yet undiscovered components of DIC uptake systems are present in $C$. reinhardtii that compensate for the loss of the Ccps in the chloroplast envelope. This may be the reason why several laboratories have not reported on high- $\mathrm{CO}_{2}$ requiring strains of $C$. reinhardtii that have a mutation affecting a single component involved in the active uptake of DIC. Interestingly, one CCM mutant characterized in C. reinhardtii has a defect in the regulatory protein Cia5. cia5 mutants grow slowly in a low- $\mathrm{CO}_{2}$ environment and are unable to induce, or depress, the CCM in response to changes in $\mathrm{CO}_{2}$ concentration. Since several dozen genes are under the control of Cia5, it is easy to speculate that a mutation in a single component of the DIC uptake mechanism will not lead to a CCM mutant phenotype in liquid culture, as is the case with the two Ccp proteins.

A second possible explanation for the growth characteristics of the Ccp1/2 RNAi strain is that the Ccp peptides are not DIC transporters but are required for some other aspect of growth in a low$\mathrm{CO}_{2}$ environment, for example as a transporter of metabolic intermediates involved in photorespiration. A third hypothesis is that Ccp1 and Ccp2 encode proteins similar to the bou protein described in $A$. thaliana. If this were the case, Ccp RNAi strains may be deficient in some general transport of metabolic intermediates such as acetate between the chloroplast and the cytosol. Any of these hypotheses could explain why long-term growth on solid media in a low- $\mathrm{CO}_{2}$ environment leads to a slow-growth phenotype in the RNAi strains.

By silencing the expression of the Ccp proteins, this work provides evidence that $\mathrm{Ccp}$ is required for normal growth in a low- $\mathrm{CO}_{2}$ environment, but not absolutely required for efficient photosynthesis at low concentrations of $\mathrm{CO}_{2}$. Further biochemical analyses will be required to determine the role of the Ccps in a low- $\mathrm{CO}_{2}$ environment in C. reinhardtii.

\section{Acknowledgements}

The authors would like to thank Dr. Arthur Grossman for critically reading the manuscript before submission. This work was supported by NSF grant IBN-0212093 to JVM and HHMI to ACG and DLP.

\section{References}

Burow, M.D., Chen, Z.-Y., Mouton, T.M. and Moroney, J.V. 1996. Isolation of cDNA clones induced upon transfer of Chlamydomonas reinhardtii cells to low $\mathrm{CO}_{2}$. Plant Mol. Biol. 31: 443-448.

Chen, Z.-Y., Lavigne, L.L., Mason, C.B. and Moroney, J.V. 1997. Cloning and overexpression of two cDNAs encoding the low $\mathrm{CO}_{2}$-inducible chloroplast envelope protein LIP-36 from Chlamydomonas reinhardtii. Plant Physiol. 114: 265-273.

Fukuzawa, H., Ishizaki, K., Miura, K., Matsueda, S., Ino-ue, T., Kucho, K. and Ohyama, K. 1998. Isolation and characterization of high $\mathrm{CO}_{2}$ requiring mutants from Chlamydomonas reinhardtii by gene tagging. Can. J. Bot. 76: 1092-1097.

Fukuzawa, H., Miura, K., Ishizaki, K., Kucho, K., Saito, T., Kohinata, T., and Ohyama, K. 2001. Ccm1, a regulatory gene controlling the induction of a carbon-concentrating mechanism in Chlamydomonas reinhardtii by sensing $\mathrm{CO}_{2}$. Proc. Natl. Acad. Sci. USA 98: 5347-5352.

Geraghty, A.M., Anderson, J.C. and Spalding, M.H., 1990. A 36 kilodalton limiting- $\mathrm{CO}_{2}$ induced polypeptide of Chlamydomonas is distinct from the 37 kilodalton periplasmic carbonic anhydrase. Plant Physiol. 93: 116-121.

Im, C.S., Zhang, Z., Shrager, J., Chang, C.W. and Grossman, A.R. 2003. Analysis of light and $\mathrm{CO}_{2}$ regulation in Chlamydomonas reinhardtii using genome-wide approaches. Photosyn. Res. 75: 111-125.

Koblenz, B., Schoppmeier, J., Grunow, A. and Lechtreck, K.F. 2003. Centrin deficiency in Chlamydomonas causes defects in basal body replication, segregation and maturation. J. Cell Sci. 116: 2635-2646.

Lawand, S., Dorne A.J., Long D., Coupland, G., Mache, R. and Carol, P. 2002. Arabidopsis A BOUT DE SOUFFLE, which is homologous with mammalian carnitine acyl carrier, is required for postembryonic growth in the light. Plant Cell. 14: $2161-2173$.

Marek, L.F. and Splading, M.H. 1991. Changes in photorespiratiory enzyme activity in response to limiting $\mathrm{CO}_{2}$ in Chlamydomonas reinhardtii. Plant Physiol. 97: 420-425.

Moroney, J.V., Husic H.D., Tolbert, N.E., Kitayama, K., Manuel, L.J. and Togasaki, R.K. 1989. Isolation and characterization of a mutant of Chlamydomonas reinhardtii deficient in the $\mathrm{CO}_{2}$ concentrating mechanism. Plant Physiol. 89: 897-903.

Moroney, J.V. and Mason, C.B. 1991. The role of the chloroplast in $\mathrm{C}_{\mathrm{i}}$ uptake in Chlamydomonas reinhardtii. Can. J. Bot. 69: 1017-1024.

Moroney, J.V. and Somanchi, A. 1999. How algae concentrate $\mathrm{CO}_{2}$ to increase the efficiency of photosynthetic carbon fixation. Plant Physiol. 119: 9-16.

Omata, T., Takahashi, Y., Yamaguchi, O. and Nishimura, T. 2002. Structure, function and regulation of the cyanobacterial high affinity bicarbonate transporter, Bctl. Funct. Plant Biol. 29: 151-159.

Pollock, S.V. and Colman, B. 2001. The inhibition of the carbon concentrating mechanism of the green alga 
Chlorella saccharophila by acetazolamide. Physiol. Plant 111: 527-532.

Pollock, S.V., Colombo, S.L., Prout, D.L. Jr., Godfrey, A.C. and Moroney, J.V. 2003. Rubisco activase is required for optimal photosynthesis in the green alga Chlamydomonas reinhardtii in a low $\mathrm{CO}_{2}$ atmosphere. Plant Physiol. 133: 1854-1861.

Ramazanov, Z., Mason, C.B., Geraghty, A.M., Spalding, M.H. and Moroney, J.V. 1993. The low $\mathrm{CO}_{2}$-inducible $36 \mathrm{kDa}$ protein is localized to the chloroplast envelope of Chlamydomonas reinhardtii. Plant Physiol. 101: 11951199.

Rawat, M. and Moroney, J.V. 1995. Regulation of carbonic anhydrase and ribulose-15-bisphosphate carboxylase/oxygenase activase by light and low $\mathrm{CO}_{2}$ in Chlamydomonas reinhardtii. Plant Physiol. 109: 937-944.

Shibata, M., Ohkawa, H., Katoh, H., Shimoyama, M. and Ogawa, T. 2002. Two $\mathrm{CO}_{2}$ uptake systems: four systems for inorganic carbon acquisition in Synechocystis sp. strain PCC6803. Funct. Plant Biol. 29: 123-129.

Shimogawara, K., Fujiwara, S., Grossman, A. and Usuda, H. 1998 High efficiency transformation of Chlamydomonas reinhardtii by electroporation. Genetics 148: 1821-1828.

Sineshchekov, O.A., Jung, K.H. and Spudich, J.L. 2002. Two rhodopsins mediate phototaxis to low and high intensity light in Chlamydomonas reinhardtii. Proc. Natl. Acad. Sci. USA 99:8689-8694.

Somanchi, A., Handley, E.R. and Moroney, J.V. 1998. Chlamydomonas reinhardtii cDNAs upregulated in low $\mathrm{CO}_{2}$ conditions: expression and analysis. Can. J. Bot. 76: 10031009.

Spalding M.H. and Jeffrey M. 1989. Membrane-associated polypeptides induced in Chlamydomonas by limiting $\mathrm{CO}_{2}$ concentrations. Plant Physiol. 89: 133-137.

Spalding, M.H., Winder, T.L., Anderson, JC, Geraghty, A.M. and Marek, L.F. 1991. Changes in protein and gene expression during induction of the $\mathrm{CO}_{2}$-concentrating mechanism in wild-type and mutant Chlamydomonas. Can. J. Bot. 69: 1008-1016.

Sueoka, N. 1960. Mitotic replication of deoxyribonucleic acids in Chlamydomonas reinharditii. Proc. Natl. Acad. Sci. USA 46: 83-91.

Walker, J.E. and Runswick, M.J. 1993. The mitochondrial transport protein superfamily. J. Bioenerg. Biomemb. 25: 435-446.

Xiang, Y.B., Zhang, J. and Weeks, D.P. 2001. The Cia5 gene controls formation of the carbon concentrating mechanism in Chlamydomonas reinhardtii. Proc. Natl. Acad. Sci. USA 98: 5341-5346. 